\title{
Professional motivation of employees of internal affairs bodies as a factor of personnel potential management in the system of the Ministry of internal affairs of Russia
}

\author{
Anton Sergeevich Dushkin*, Natalia Andreevna Goncharova, Tatyana Fedorovna Fomina, \\ Asel Azilbekovna Sarsenova, and Aleksandra Arturovna Kalashnik
}

Saint Petersburg University of the Ministry of Internal Affairs of Russia, Department of Pedagogy and Psychology, Saint Petersburg, Russia

\begin{abstract}
Professional motivation of employees of internal affairs bodies is a significant factor in the management of personnel potential and requires systematic monitoring of indices determining the motivational readiness for the activities of the subjects of the law enforcement sphere. It is determined by indices that reflect the essence of personnel potential, which depends largely on both the psychological parameters of employee motivation and the psychological and pedagogical competence of managers. Structured operational and service tasks are very important in the motivation management or support the importance of employee performance. The systematic monitoring of motivation level ensures its stability and creates conditions for a qualitative prediction of reliability and effectiveness of the subject. The conducted empirical research of motivational profile shows that the motivation level of subjects of professional activity of internal affairs bodies, at the initial stages of professional genesis, is significantly higher and differs by the moral and business nature of orientation from similar indices of subjects at the later stages of professional activity. At the same time, the overall motivation level, regardless of length of service, is mainly represented by average normative indices. The results of the research suggest that in order to ensure the effectiveness of motivation management one should pay attention to the identified values of motivation, reflecting the high need for employees to structure activities, getting feedback on their performance, reducing the uncertainty of the rules and directives of the job, the need to maintain long-term and stable relationships with colleagues.
\end{abstract}

Keywords: personnel potential, motivation, professional development, professional genesis

\section{Introduction}

The effectiveness of the official activities of employees of the organization is determined by the consistency of management decisions aimed at the formation of human resources capacity

*Corresponding author: dushkin-ac@mail.ru 
of internal affairs bodies, represented by a set of professional opportunities, personal characteristics of personnel and indices of the moral and psychological state [1]. Improving the quality of human resources potential of internal affairs bodies is considered to be one of the objectives of personnel policy outlined in the draft Concept of Personnel Policy of the Ministry of Internal Affairs of the Russian Federation in the bodies of internal affairs. The quality of human resources is a necessary basis for achieving the goals and objectives set for the internal affairs bodies $[2,3]$.

The effectiveness of human resource management in an organization is determined by a set of factors of organizational, economic and psychological nature [4-7]. Among the most relevant are factors of professional motivation, considered as a set of conditions that motivate employees to activity, stimulate inner potential of the individual, and directing the efforts of the subject of labor to achieve the professional goal.

Kibanov calls motivation to work a cohesive function of personnel management [8]. In implementing this function within the framework of personnel policy, a system of influences on the behavior of employees is developed. Its purpose is the effective use of potential and the successful achievement of the organization's objectives. Motivation is a significant resource of personnel management, so consistently relevant is the task of "motivating" employees, which, according to Karpov, is the most psychological among "all other management decisions" [9].

In modern conditions, the motivation of employees of internal affairs bodies is evaluated at the stage of professional psychological selection for service in the internal affairs bodies [10]. Subsequent evaluation of motivation is practically unavailable. Accordingly, the existing recommendations on motivation management remain at the level of declarative proposals.

Motivational sphere of the subject of professional activity is represented by a system of personal meanings and has a significant reserve for the development of professionalism, competence and efficiency [11]. The elements that make up the motivational sphere are the human motivator in the profession, which, from Markova's point of view, allows the subject to voluntarily, strive to achieve the best results and compensate for the lack of technological skills based on inner motivations of a spiritual nature [12]. Internal motives for activity form the basis of the spiritual content of the profession, which include achievement motivation, focus on the profession, its ideals and values, the desire for self-realization and selfimprovement, job satisfaction, readiness for flexible reorientation within the profession, stability and harmony at all stages of professional development [12].

In this connection, the urgent tasks of determining the activity of the subject of labor at each stage of professional genesis, which allow, with the help of motivation, to provide an increase in general psychological readiness and prevent professional deformations, must be solved [13]. The scope of tasks is determined not only by the qualitative characteristics of the incentive system and the satisfaction of the primary needs of the employee. Essential are organizational means, monitoring and analysis of psychological features of professional motivation of personnel, focus on psychological methods of motivation management, understanding the dependence of individual effectiveness of the subject on the level of internal motivational readiness [14-16].

\section{Methods}

The study was aimed at studying the specifics of motivation of employees of the internal affairs bodies at different stages of professional development. The test of the hypothesis of the significant differences of the progressive character in the motivational profile of the personality of subjects of professional activity depending on the stage of professional development was carried out in the course of the research. Standardized psychical evaluation 
tools were used to obtain representative material that would allow us to assess the motivational profile of the personality and type of motivation of employees: Modified questionnaire "Motivational profile" by S. Ritchie and P. Martin, questionnaire "Assessment of motivation types" by Gerchikov, questionnaire "Assessment of pretension level" by Gerbachevsky. Mathematical analysis was carried out with the help of statistical package "SPSSStatistics 21".

The sample of the study was represented by a total of 65 people, of whom $100 \%$ were male representatives, comprising two groups with different length of service in the internal affairs bodies. The first group includes employees with up to one year of service in the internal affairs bodies, the second group with more than five years of service.

\section{$3 \quad$ Results}

The research conducted on the motivational profile indices of the personality revealed that a number of motivation traits are within the range of above-average normative values: "need for wages" $(28.11 \pm 7.4$ / 38.41 $\pm 1.01 ; \mathrm{p} \leq 0.03)$, "working conditions" (27.02 \pm 9.01 / $29.71 \pm 9.22)$, "job structuring" (39.9 \pm 11.2 / 33.6 \pm 11.4$)$, "social contacts" (34.6 \pm 9.03$)$, "relationships" (22.3 \pm 8.2 / 27.3 \pm 13.1$)$. Peculiarities of the motivation type in the group of employees with up to one year of service are characterized by the dominance of the "professional type". The leading type of motivation in the group with high length of service is "instrumental", with a reliably high motivation level of "high earnings" as the main result of work.

The study of indices of motivational attraction components allowed to establish normative average values in both groups. At the same time, comparatively lower values of the general index of the level of pretensions were revealed in the group with a high experience of professional activity. At the initial stage of professional genesis, the priority motives of internal character $(13,01 \pm 2,9 / 9,9 \pm 2,01 ; p \leq 0,01)$, cognitive $(13,9 \pm 2,9 / 10,1 \pm 1,9 ; p \leq 0.01)$, competitive motives $(14.01 \pm 2.01 / 9.2 \pm 2.3 ; \mathrm{p} \leq 0.0001)$, self-esteem $(12.6 \pm 5.9 / 10.9 \pm 1.5$; $\mathrm{p} \leq 0.01)$, activity result values $(12.1 \pm 2.8 / 8.9 \pm 1.01 ; \mathrm{p} \leq 0.01)$. In the later stages of professional genesis there are significantly lower rates of respondents' assessment of their own potential, "intended level of effort mobilization" $(14.1 \pm 3.2 / 11.2 \pm 1.6 ; \mathrm{p} \leq 0.01)$ "initiative" (14.3 $\pm 1.9 / 9.8 \pm 1.9 ; \mathrm{p} \leq 0.01)$, "expectation of activity results pattern" $(12.9 \pm 2.01$ / 11.07 $\pm 1.99 ; \mathrm{p} \leq 0.01)$.

\section{Discussion}

The results of the research of the motivational profile showed that the motivation level of the subjects of the studied sphere of professional activity is determined mainly by the average indices, regardless of the length of service. The assumption of a high motivation level at the stage of professionalism and the presence of intrinsic motivation in the overall motivational structure is not confirmed. The established significant differences between the indices of motivation of subjects of activity at different stages allow to note a reliably high motivation level only at the initial stages of professional activity, which requires managerial attention and correction of ways of interaction with staff.

In the analysis of the general motivational profile of all employees, a low level of values of the indices "recognition", "achievement", "diversity", "creativity", "self-improvement" "interesting work" draws attention. The totality of these attributes reflects the spiritual orientation of professional motivation that determines service and professionalism. Motivation of subjects with a long service record for high wages and favorable contacts established. Differences in types of motivation are evidence of a relatively lower level of 
professional motivation at the stage of professionalism, which is reflected in the manifestations of professional deformation: lack of aspirations for development, lack of initiative, focus on simple tasks, narrowing of functional responsibilities. The priorities of the instrumental type of motivation are associated with the appropriate type of management tasks, in which the psychological factors of motivation of personnel are practically not taken into account.

The study showed that the core of the motivational structure of each group is characterized by fundamentally different values. They reflect the average level of cognitive activity, interest in activity, competitiveness, striving to exceed the results of activity, the need for self-esteem in the first period of professional activity.

Thus, the hypothesis that there are progressive differences between the motivation indices of employees with a short and long service record was not confirmed. Performed professional activity is mainly the result of self-motivation of employees, in which the most significant factors are indices of pragmatic orientation.

\section{Conclusion}

Development and implementation of the system of diagnostics of professional motivation of the Ministry of Internal Affairs employees at different stages of service is one of the most important directions in the implementation of measures to improve the efficiency of the use of human resources in the system of the Ministry of Internal Affairs of Russia. It would provide a full and comprehensive study and analysis of personnel characteristics, service capabilities and abilities of employees, the presence of their necessary professional competencies, motivation for service activities, and, accordingly, the preparation of objective data for making optimal management decisions.

\section{References}

1. O.V. Shkola, Vestnik of Moscow University of the Ministry of Internal Affairs of Russia, 8, 221 (2014)

2. E.A. Nikolaenko, Problems of Law Enforcement Activity, 2, 35 (2018)

3. E.F. Rybakova, Vestnik of Moscow University of the Ministry of Internal Affairs of Russia, 11, 189 (2015)

4. S.S. Zhevlakovich, Vestnik of Moscow University of the Ministry of Internal Affairs of Russia, 5, 301 (2017)

5. T.V. Ignatova, V.I. Kozachok, L.A. Pashin, Central Russian Journal of Social Sciences, 10(6), 34 (2015). https://doi.org/10.12737/16789

6. O.S. Kraynova, D.M. Satayeva, Bulletin of Moscow University named after S.Y. Witte. Series 1 "Economics and management", 26(3), 77 (2018)

7. N.M. Kurshieva, Voprosy Upravleniya, 1, 25 (2013)

8. A.Ya. Kibanov, L.V. Ivanovskaya, Kadrovaya politika i strategiya upravleniya personalom [Personnel Policy and Strategy of Personnel Management: practical manual] (Prospect Publ., Moscow, 2014)

9. A.V. Karpov, Psikhologiya menedzhmenta [Psychology of Management: textbook] (Yurait Publ., Moscow, 2019)

10. L.Y. Nezhkina, Eurasian Law Journal, 11(114), 346 (2017)

11. L.Y. Nezhkina, I.V. Yaroslavtseva, Vestnik of the Saint Petersburg University of the Ministry of Internal Affairs of Russia, 3(71), 200 (2016) 
12. A.K. Markova, Psikhologiya professionalizma [Psychology of professionalism: monograph] (Mezhdunar. gumanitar fond "Znanie" Publ., Moscow, 1996)

13. N.A. Goncharova, Herald of Tver State University. Series: Pedagogy and Psychology, 3, 11 (2018)

14. A. Olšovská, M. Švec, Use of Psychological Examinations of Employees and Job Applicants in Personnel Management, in L. Mura (ed.), Issues of Human Resource Management, ch. 2 (IntechOpen, 2017). https://doi.org/10.5772/67868

15. R.E. Cocharane, R.P. Tett, L. Vandecreek, Criminal Justice and Behavior, 30(5), 511 (2003). https://doi.org/10.1177/0093854803257241

16. J.G. Varela, M.T. Boccaccini, F. Scogin, J. Stump, A. Caputo, Criminal Justice and Behavior, 3(6), 649 (2004). https://doi.org/10.1177/0093854804268746 